\title{
Downregulation of nucleolar and spindle-associated protein 1 expression suppresses cell migration, proliferation and invasion in renal cell carcinoma
}

\author{
LU FANG ${ }^{1,2^{*}}$, MENG ZHANG ${ }^{2,3 *}$, LEI CHEN $^{1,2^{*}}$, HU XIONG $^{4}$, YUKUN GE $^{5}$, WEI LU $^{2,3}$,

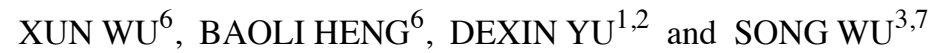 \\ ${ }^{1}$ Department of Urology, The Second Affiliated Hospital of Anhui Medical University, Hefei, Anhui 230601; \\ ${ }^{2}$ Department of Urology, Anhui Medical University, Hefei, Anhui 230032; ${ }^{3}$ Department of Urology, \\ Shenzhen Second People's Hospital, The First Affiliated Hospital of Shenzhen University, Shenzhen, Guangdong 518037; \\ ${ }^{4}$ Department of Urology, The Second Hospital of Lanzhou University, Lanzhou, Gansu 730000; \\ ${ }^{5}$ Department of Urology, Zhujiang Hospital of Southern Medical University, Guangzhou, Guangdong 510280; \\ ${ }^{6}$ Department of Urology, The First Affiliated Hospital of Jinan University, Guangzhou, Guangdong 510630; \\ ${ }^{7}$ Department of Urology, Luohu People's Hospital of Shenzhen University, Shenzhen, Guangdong 518001, P.R. China
}

Received January 4, 2016; Accepted February 15, 2016

DOI: $10.3892 / o r .2016 .4955$

\begin{abstract}
Nucleolar and spindle-associated protein 1 (NUSAP1) is a microtubule-binding protein that plays an essential role in mitosis and cancer. Previous studies have demonstrated that NUSAP1 expression is relatively elevated in several malignancies. However, the biological roles of NUSAP1 in renal cell carcinoma (RCC) remain unknown. In the present study, we firstly performed reverse transcription-polymerase chain reaction (RT-PCR) and western blot analysis to reveal that the expression of NUSAP1 was relatively elevated in clear cell RCC (ccRCC) tissue specimens and RCC cell lines. Immunohistochemical analysis showed that upregulation of NUSAP1 was significantly correlated with Fuhrman grade $(\mathrm{P}<0.001)$, tumor size $(\mathrm{P}=0.016)$, clinical stage $(\mathrm{P}<0.001)$ and distant metastasis $(\mathrm{P}=0.023)$. Additionally, high expression of NUSAP1 was closely associated with a shorter overall survival time of the ccRCC patients $(\mathrm{P}=0.006)$. Furthermore, we investigated the biological behaviors of RCC cells in vitro, and we identified that NUSAP1 depletion inhibited RCC cell migra-
\end{abstract}

Correspondence to: Professor Dexin Yu, Department of Urology, The Second Affiliated Hospital of Anhui Medical University, Hefei, Anhui 230601, P.R. China

E-mail: yudx_urology@126.com

Professor Song Wu, Shenzhen Second People's Hospital, The First Affiliated Hospital of Shenzhen University, Shenzhen, Guangdong 518037, P.R. China

E-mail: doctor_wusong@126.com

${ }^{*}$ Contributed equally

Key words: NUSAP1, RCC, migration, proliferation, invasion, prognosis tion, proliferation and invasion, and apoptosis was induced and the cell cycle was arrested. On the basis of our studies, NUSAP1 was identified as a potential prognostic indicator and a novel therapeutic target for RCC patients.

\section{Introduction}

Renal cell carcinomas (RCCs) are the most common cancers that originate from the renal parenchyma, and account for approximately $90 \%$ of all adult kidney malignancies (1). The major histologic subtype of RCC is clear cell RCC (ccRCC) that represents $70-80 \%$ of RCCs, followed by papillary (10-20\%), chromophobe (5\%) and collecting duct $(1 \%)$ subtypes (2). Globally, the incidence of kidney cancer is approximately 270,000 new cases and 116,000 deaths, annually (3). Despite considerable improvements in the diagnosis and treatment of RCCs in recent years, nearly 20-30\% of all patients present with metastasis at the time of initial diagnosis, and approximately $20 \%$ of RCC patients who undergo nephrectomy may suffer recurrence or metastasis of the disease (4). For these patients, the prognosis is extraordinarily poor and median survival is not more than one year (5). Therefore, it is of great necessity to investigate the underlying molecular mechanisms of the tumorigenesis and progression of RCC. Identifying more novel biomarkers is still required to promote early diagnosis, targeted therapy and prognosis evaluation.

Nucleolar and spindle-associated protein 1 (NUSAP1) is a recently identified protein with a molecular weight of $55 \mathrm{kDa}$ that plays a crucial role in spindle microtubule organization (6). NUSAP1 exhibits a cell cycle-dependent localization and is selectively expressed in proliferating cells. Its mRNA and protein expression levels reach a peak at the transition of $\mathrm{G}_{2}$ to mitosis and then rapidly decline after cell division (7). The depletion and overexpression of NUSAP1 in cells result in abnormal chromosome segregation, aberrant spindle assembly, 
defective cytokinesis, $\mathrm{G}_{2} / \mathrm{M}$ arrest and microtubule bundling, respectively $(7,8)$.

In addition to playing an essential role in mitosis, NUSAP1 has recently attracted broad attention for its involvement in cancers. Previous studies have shown that elevated expression of NUSAP1 is correlated with malignancies, including pancreatic adenocarcinoma, melanoma, glioblastoma, hepatocellular carcinoma, and prostate cancer (9-13). NUSAP1 has also been associated with the aggressiveness of meningioma (11), high risk and poor outcome in breast cancers $(14,15)$. In contrast, a study of childhood ALL revealed that the expression level of NUSAP1 was decreased in patients presenting with a poor prognosis (16). These findings suggest a critical role of NUSAP1 in the initiation and progression of human cancers.

To date, rare research has been conducted on the expression and clinical significance of NUSAP1 in RCCs. In the present study, the expression of NUSAP1 was firstly evaluated in both ccRCC tissues and RCC cell lines by reverse transcription-polymerase chain reaction (RT-PCR), western blot (WB) assay and immunohistochemistry (IHC) assays. Then, we immunohistochemically analyzed its expression and correlation with clinicopathological characteristics of the ccRCC patients. The present study demonstrated that there was a close relationship between NUSAP1 expression and the prognosis of ccRCC patients. Furthermore, we investigated the biological behavior of human RCC cells after downregulation of NUSAP1 expression in vitro, which suggested that overexpression of NUSAP1 was associated with cell migration, proliferation and invasion of RCC.

\section{Materials and methods}

Patients and tissue specimens. For the RT-PCR analysis, 38 pairs of ccRCC tissue specimens and matched adjacent normal tissues were collected from patients who underwent radical nephrectomy at the Second Affiliated Hospital of Anhui Medical University (Anhui, China) between March 2010 and August 2012. In addition, we prepared 124 paraffin-embedded ccRCC samples for immunohistochemical analysis from Zhujiang Hospital of Southern Medical University (Guangzhou, China) between January 2006 and February 2010. Each case was histologically confirmed as ccRCC and with a verification of no preoperative chemotherapy or radiotherapy. The patients enrolled in the immunohistochemical analysis had been followed up until February 2015 with a median follow-up period of 51.5 months (5-60 months). Clinicopathological data of these patients including age, gender, tumor size, Fuhrman grade, clinical stage, lymphatic and distant metastasis (Table I) were gathered from well-documented medical records. Tumor stage and grade were classified according to the American Joint Commission on Cancer (AJCC) tumor, nodes and metastasis (TNM) system and Fuhrman criteria. The patients enrolled in the present study had given written informed consent, and the study was approved by the Ethics Committee of The Second Affiliated Hospital of Anhui Medical University and Zhujiang Hospital of Southern Medical University.

Cell culture and transfection. Four human RCC cell lines (786-O, A704, ACHN and A498) and an immortalized normal human proximal tubule epithelial cell line HK-2 were purchased from the Cell Bank of the Type Culture Collection of the Chinese Academy of Sciences (Shanghai, China) and the American Type Culture Collection (ATCC; Rockville, MD, USA), respectively. HK-2 cells were cultured in K-SFM medium, while RCC cells were cultured in Dulbecco's modified Eagle's medium (DMEM), both supplemented with $10 \%$ fetal bovine serum (FBS) and $1 \%$ penicillin-streptomycin (both from Gibco, Carlsbad, CA, USA). All cells were cultured in a sterile incubator under the condition of $5 \% \mathrm{CO}_{2}$ at $37^{\circ} \mathrm{C}$. The small interfering RNA (siRNA) targeting NUSAP1 (si-NUSAP1) and scrambled siRNA (si-NC, as negative control) were purchased from GenePharma (Shanghai, China). The sequence designed for si-NUSAP1 was: 5'-GCACCAAGA AGCUGAGAAUTTAUUCUCAGCUUCUUGGUGCTT-3'. RCC cell lines 786-O and A704 were transfected with either si-NUSAP1 or si-NC using Lipofectamine 2000 reagent (Invitrogen, Carlsbad, CA, USA) following the manufacturer's instructions. Forty-eight hours after transfection, the mRNA and protein were harvested and analyzed.

Real-time quantitative RT-PCR. RNA isolation from the RCC cells and tissue samples was performed using TRIzol reagent (Invitrogen) in accordance with the manufacturer's instructions. The first-strand cDNA was synthesized by RNA using MMLV reverse transcriptase (Takara, Otsu, Japan) following the protocol provided. Real-time quantitative RT-PCR (qRT-PCR) was operated using SYBR Premix Ex Taq ${ }^{\mathrm{TM}}$ kit (Takara) on an ABI 7500 RT-PCR System (Applied Biosystems, Foster City, CA, USA). The primer sequences designed for cDNA amplification were as follows: NUSAP1, 5'-GAAGCTGAGAGACAGCCACT-3' (forward), and 5'-TCT GTGAGTCAGGGTCCACA-3' (reverse); and glyceraldehyde3-phosphate dehydrogenase (GAPDH, a housekeeping gene), 5'-GAAAGCCTGCCGGTGACTAA-3' (forward), and 5'-GCC CAATACGACCAAATCAGAG-3' (reverse). The $2^{-\Delta \Delta C t}$ method (17) for calculating the relative levels of NUSAP1 mRNA was applied in the present study, and all experiments were accomplished in triplicate.

WB assay. Human RCC cells or tissue samples were lysed in RIPA buffer containing proteinase inhibitor cocktails. After centrifugation at $12,000 \mathrm{rpm}$ for $20 \mathrm{~min}$, the BCA protein assay kit (Sigma, St. Louis, MO, USA) was used to quantify the protein concentrations. Equivalent amounts of harvested proteins $(50 \mu \mathrm{g})$ were separated using SDS-PAGE, and transferred onto polyvinylidene difluoride (PVDF) membranes (Bio-Rad, Hercules, CA, USA). After being blocked with $5 \%$ bovine serum albumin (BSA) in Tris-buffered saline and Tween-20 (TBST) for $2 \mathrm{~h}$, the membranes were incubated overnight at $4^{\circ} \mathrm{C}$ with the following antibodies: rabbit polyclonal anti-NUSAP1 (Thermo Fisher Scientific, Inc., Waltham, MA, USA), and goat polyclonal anti-GAPDH (Santa Cruz Biotechnology, Santa Cruz, CA, USA). Then, the membranes were washed and incubated with secondary antibodies at room temperature for $1 \mathrm{~h}$. Proteins were finally visualized using ECL immunoblotting detection reagent (Biobox Biotech. Co., Ltd, Nanjing, China) according to the manufacturer's instructions.

IHC and staining analysis. IHC was performed to determine the protein level of NUSAP1 expression in the ccRCC and 
Table I. Relationship between NUSAP1 expression and clinicopathological characteristics of the ccRCC patients.

\begin{tabular}{|c|c|c|c|c|c|}
\hline \multirow[b]{2}{*}{ Variable } & \multirow[b]{2}{*}{ Cases n $(\%)$} & \multicolumn{2}{|c|}{ NUSAP1 expression } & \multirow[b]{2}{*}{$\chi^{2}$} & \multirow[b]{2}{*}{ P-value } \\
\hline & & High n $(\%)$ & Low n $(\%)$ & & \\
\hline Gender & & & & 0.108 & 0.743 \\
\hline Male & $80(64.5)$ & $43(53.8)$ & $37(46.2)$ & & \\
\hline Female & $44(35.5)$ & $25(56.8)$ & $19(43.2)$ & & \\
\hline Age (years) & & & & 3.016 & 0.082 \\
\hline$\leq 50$ & $43(34.5)$ & $19(44.2)$ & $24(55.8)$ & & \\
\hline$>50$ & $81(65.5)$ & $49(60.5)$ & $32(39.5)$ & & \\
\hline Fuhrman grade & & & & 18.243 & $<0.001^{\mathrm{a}}$ \\
\hline $\mathrm{G} 1-\mathrm{G} 2$ & $84(67.7)$ & $35(41.7)$ & $49(58.3)$ & & \\
\hline G3-G4 & $40(32.3)$ & $33(82.5)$ & $7(17.5)$ & & \\
\hline Tumor size (cm) & & & & 5.816 & $0.016^{\mathrm{a}}$ \\
\hline$\leq 7.0$ & $86(69.4)$ & $41(47.7)$ & $45(52.3)$ & & \\
\hline$>7.0$ & $38(30.6)$ & $27(71.1)$ & $11(28.9)$ & & \\
\hline Clinical stage & & & & 16.187 & $<0.001^{\mathrm{a}}$ \\
\hline I-II & $94(75.8)$ & $42(44.7)$ & $52(55.3)$ & & \\
\hline III-IV & $30(24.2)$ & $26(86.7)$ & $4(13.3)$ & & \\
\hline Lymph node metastasis & & & & 3.015 & 0.082 \\
\hline No & $108(87.1)$ & $56(51.9)$ & $52(48.1)$ & & \\
\hline Yes & $16(12.9)$ & $12(75.0)$ & $4(25.0)$ & & \\
\hline Distant metastasis & & & & 5.199 & $0.023^{\mathrm{a}}$ \\
\hline No & $111(89.5)$ & $57(51.4)$ & $54(48.6)$ & & \\
\hline Yes & $13(10.5)$ & $11(84.6)$ & $2(15.4)$ & & \\
\hline
\end{tabular}

${ }^{a} \mathrm{P}<0.05$. NUSAP, nucleolar and spindle-associated protein 1; RCC, renal cell carcinoma; ccRCC, clear cell RCC.

matched adjacent normal tissues using EliVision method for IHC staining. All formalin-fixed and paraffin-embedded samples were cut in $4-\mu \mathrm{m}$ thick sections, deparaffinized and dehydrated. These sections were soaked in $3 \% \mathrm{H}_{2} \mathrm{O}_{2}$ to block endogenous peroxides, then, immerged in effervescent citrate buffer (10 mM,pH 6.0) and incubated with 5\% BSA for $30 \mathrm{~min}$, respectively. Thereafter, the slides were incubated overnight at $4^{\circ} \mathrm{C}$ with primary rabbit polyclonal anti-NUSAP1 antibody (1:50; Thermo Fisher Scientific), and further incubated with the secondary antibody on the next day. The DAB kit (ZSGB-Bio, Beijing, China) was used to perform the visualization. The slides were washed in distilled water and counterstained with hematoxylin at the end of the staining process.

IHC staining results were measured based on the multiplication of staining intensity and density scores. The intensity score was calculated according to the average intensity of positive NUSAP1-staining cells ( 0 , none; 1 , weak; 2 , moderate; 3 , strong). The density score was calculated from the results of the percentage of positive-staining cells $(1,<5 \% ; 2,5-25 \%$; $3,>25-50 \% ; 4,>50 \%$ ). The overall score was finally determined, and scores of 0-4 were defined as low expression while scores $>4$ were considered as high expression. The immunohistochemical staining was evaluated by two independent observers blinded to the clinical outcomes.

Scratch migration assay. Cell migration ability was determined by scratch migration assay. 786-O and A704 cells transfected with the negative control (si-NC) or si-NUSAP1 were seeded into 6-well plates at a concentration of $5 \times 10^{5}$ cells/well and cultured overnight. Then, the monolayer cells were scratched with a sterile $10-\mu 1$ pipette tip, washed thrice with phosphate-buffered saline (PBS) and incubated at $37^{\circ} \mathrm{C}$ in $5 \%$ $\mathrm{CO}_{2}$. The wound closure was observed and photographed by a inversion fluorescence microscope (Olympus, Tokyo, Japan) after $24 \mathrm{~h}$. Each experiment was performed in triplicate.

Cell invasion assay. Transwell invasion assay was conducted on a 24-well Transwell chamber plates with a pore size of $8 \mu \mathrm{m}$. The Transwell filter inserts were precoated with $40 \mu \mathrm{l}$ Matrigel (dilution at 1:3; BD Biosciences) at $37^{\circ} \mathrm{C}$ for 5 h. $786-\mathrm{O}$ and A704 cells $\left(1 \times 10^{5}\right.$ cells/well) were seeded in serum-free DMEM in the upper chamber, and the lower chamber contained DMEM with 10\% FBS. After incubation at $37^{\circ} \mathrm{C}$ for $24 \mathrm{~h}$, the non-invaded cells were scraped off and the invaded cells were fixed with $4 \%$ paraformaldehyde solution and stained with $0.1 \%$ crystal violet. The invaded cells were observed under a light microscope and counted in five randomly chosen fields.

Cell proliferation assay. To determine cell proliferation, 786-O and A704 cells transfected with siRNA were plated in 96-well plates at a density of $3 \times 10^{3}$ cells/well. Cell Counting Kit-8 (CCK-8; Ding Guo Biotech. Co,. Ltd, Guangzhou, China) was applied to quantify the cell proliferation at 0,12 , 
24 and $48 \mathrm{~h}$. After CCK-8 solution $(10 \mu \mathrm{l})$ was added to each well, the cells were incubated for $2 \mathrm{~h}$ at $37^{\circ} \mathrm{C}$. The absorbance that represented proliferating cell numbers was detected at $450 \mathrm{~nm}$ using a microplate reader (Thermo). Each experiment was performed in triplicate and independently repeated three times.

Flow cytometric analysis. Flow cytometric analysis was performed to determine cell apoptosis and cell cycle distribution. The Annexin V-FITC apoptosis detection kit (Beyotime-Bio, Shanghai, China) and propidium iodide (PI) was used for apoptosis assay. 786-O and A704 cells transfected with siRNA were harvested after incubation for $48 \mathrm{~h}$, washed twice by PBS and suspended in $195 \mu \mathrm{l}$ binding buffer with $5 \mu \mathrm{l}$ Annexin V-FITC, and incubated for $10 \mathrm{~min}$ at room temperature in the dark. Then, the cells were re-suspended in $190 \mu \mathrm{l}$ binding buffer with $10 \mu \mathrm{l} \mathrm{PI}$, incubated in ice water and immediately analyzed. For cell cycle analysis, 786-O and A704 cells were collected and washed twice with PBS, fixed in $75 \%$ ice-cold ethanol overnight. After that, the cells were suspended in $300 \mu \mathrm{l}$ PBS containing $20 \mu \mathrm{l}$ RNase and incubated at $37^{\circ} \mathrm{C}$ for $30 \mathrm{~min}$, and then $400 \mu \mathrm{l} \mathrm{PI}$ was added in the cell suspension, mixed and incubated at $4^{\circ} \mathrm{C}$ for $30 \mathrm{~min}$. The results were analyzed by flow cytometry (BD Biosciences) and each experiment was performed in triplicate.

Statistical analysis. All statistical analyses were analyzed using SPSS 20 statistical software (IBM, Chicago, IL, USA). Continuous data expressed as mean \pm SD were determined using the two-tailed paired Student's t-test. The Pearson's Chi-square test was performed to analyze the correlations between NUSAP1 expression and clinicopathological characteristics of the ccRCC patients. The overall survival curves were drawn according to the Kaplan-Meier method and compared using log-rank test. P-value $<0.05$ was considered to indicate a statistically significant difference.

Factors influencing the overexpression of NUSAP1. Recently, we completed reduced representation bisulfite sequencing (RRBS) and transcriptome sequencing of 34 pairs of RCC tissues and adjacent normal controls. In addition, whole-genome sequencing (WGS) was performed for another 61 paired RCC and adjacent normal tissues. All the analytical processes were referred to in our previous study (18). To date, studies related to these data have not yet been published.

\section{Results}

Increased expression of NUSAPI in ccRCC tissues and RCC cell lines. To investigate the expression of NUSAP1 at the mRNA and protein levels in ccRCC tissues, qRT-PCR and WB assay were applied in 38 pairs of ccRCC and matched adjacent normal tissues. Our results revealed that NUSAP1 was overexpressed in ccRCC tissues, when compared with levels in the matched normal tissues (Fig. 1A; $\mathrm{P}<0.001)$. In line with the mRNA data, the protein level of NUSAP1 in representative cancer tissues was also clearly higher than that in the adjacent normal tissues (Fig. 1B).

In addition, we determined the expression of NUSAP1 according to the above methods in five types of cell lines,
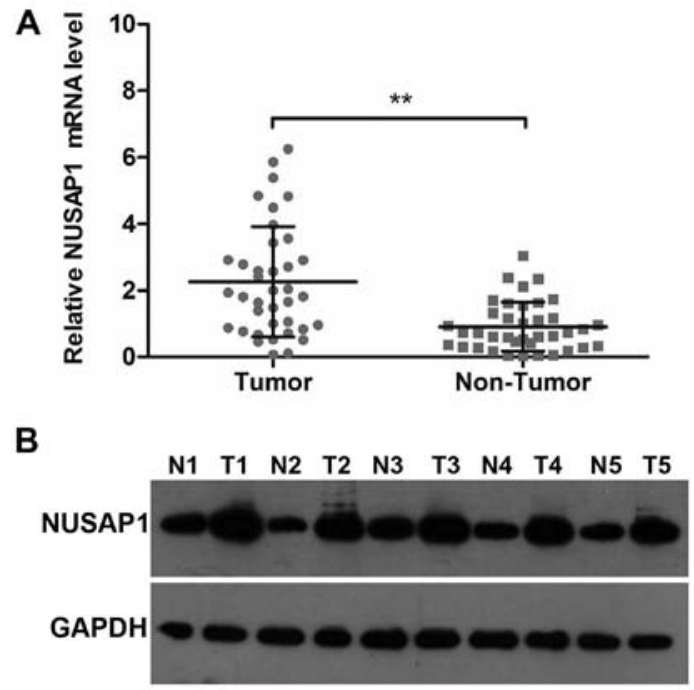

C

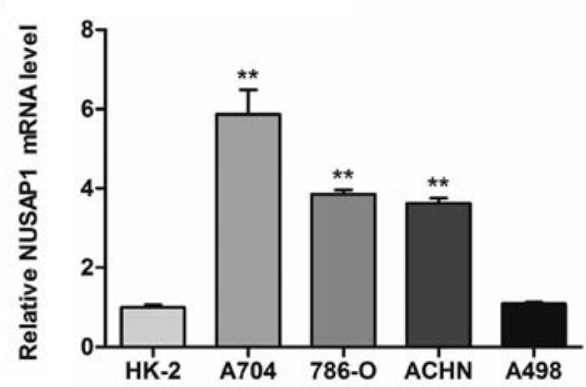

D

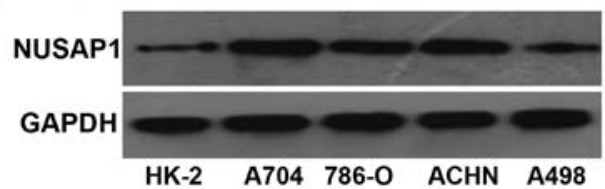

Figure 1. Expression of NUSAP1 in ccRCC tissues and RCC cell lines. (A) The mRNA level of NUSAP1 expression was determined in 38 matched pairs of ccRCC and adjacent normal tissues by qRT-PCR. (B) Expression of NUSAP1 protein was determined in five representative matched pairs of ccRCC (T) and adjacent normal tissues (N) by western blot assay. (C and D) The mRNA and protein levels of NUSAP1 expression were determined in four RCC cell lines (A704, 786-O, ACHN and A498) and HK-2 cells by qRT-PCR (C) and western blotting (D). Data are shown as mean $\pm \mathrm{SD}(\mathrm{n}=3) ;{ }^{* *} \mathrm{P}<0.001$.

including HK-2, A704, 786-O, ACHN and A498. The data revealed that NUSAP1 mRNA and protein levels were statistically elevated in three RCC cell lines (A704, 786-O and ACHN) compared with that in the HK-2 cell line (Fig. 1C and D; $\mathrm{P}<0.001)$.

Immunohistochemical analysis of NUSAPl expression in ccRCC tissues and its correlation with clinicopathological characteristics. We analyzed the protein level of NUSAP1 in 124 pieces of ccRCC sections by immunohistochemical staining. A total of $68(54.8 \%)$ cases showed high expression of NUSAP1 while 56 cases $(45.2 \%)$ revealed low expression (Fig. 2B-D). The adjacent normal tissues exhibited either no or weak staining of NUSAP1 (Fig. 2A). The relationships between NUSAP1 expression and clinicopathological characteristics of the ccRCC patients are summarized in Table I. Our data demonstrated that the expression of NUSAP1 was significantly correlated with Fuhrman grade $(\mathrm{P}<0.001)$, tumor size $(\mathrm{P}=0.016)$, clinical stage $(\mathrm{P}<0.001)$ and distant metastasis 

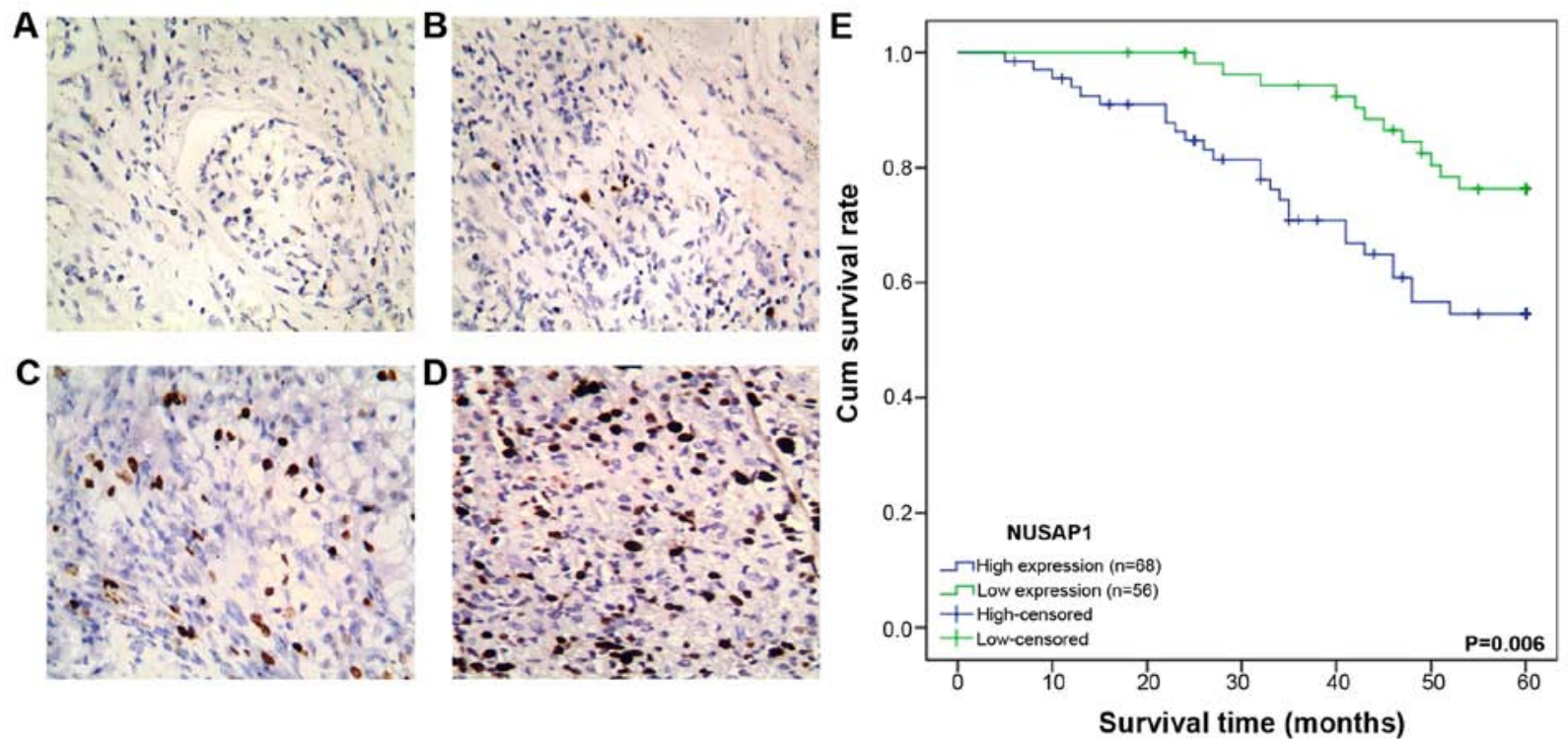

Figure 2. Immunohistochemical analysis of NUSAP1 expression in ccRCC and matched normal tissues and survival analysis of ccRCC patients. (A-D) Immunohistochemical analysis. (A) Negative or weak staining of NUSAP1 in matched adjacent normal tissues. (B) Low-level nuclear staining of NUSAP1 in cancer tissues. (C) Moderate staining of NUSAP1 in cancer tissues. (D) Strong staining of NUSAP1 in cancer tissues (magnification, x400). (E) Survival analysis. Kaplan-Meier method was applied to analyze the overall survival of ccRCC patients. The survival rate for patients with low NUSAP1 expression was significantly higher than that for patients with high NUSAP1 expression (log-rank test; $\mathrm{P}=0.006$ ).
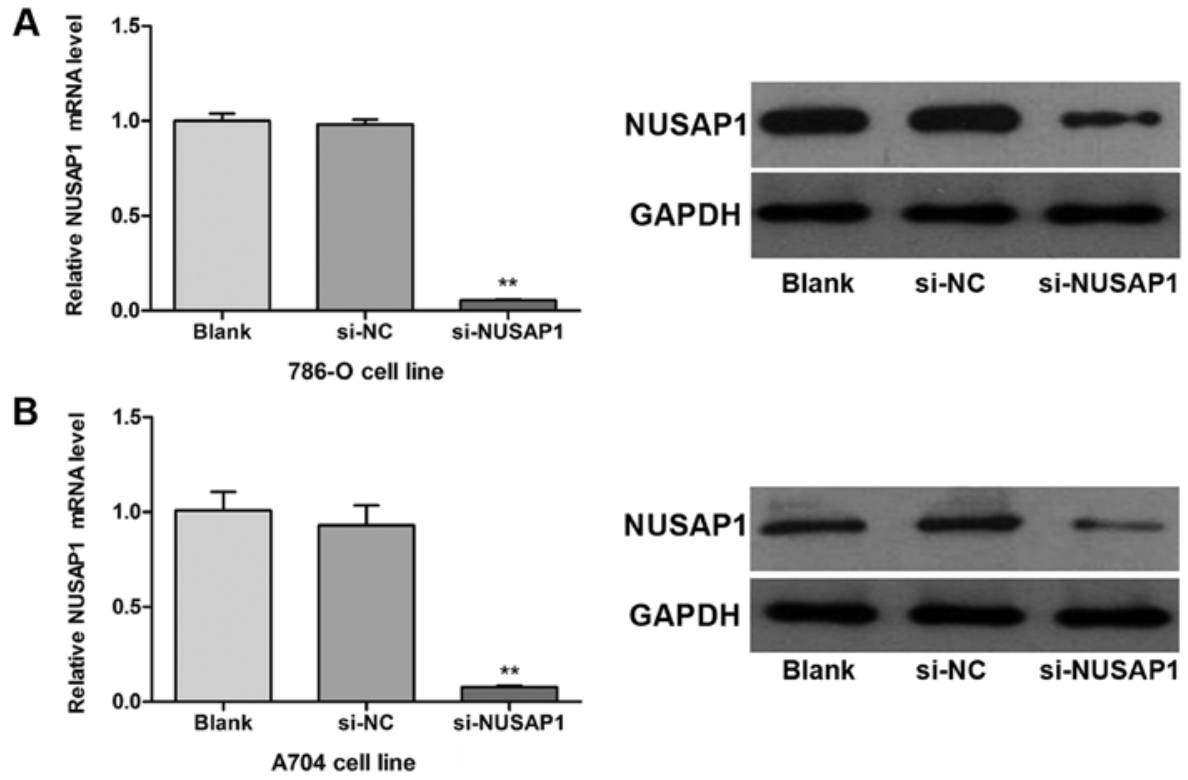

Figure 3. Expression of NUSAP1 is decreased after transfection with si-NUSAP1 in 786-O and A704 cell lines. The mRNA and protein levels of NUSAP1 expression were significantly decreased by si-NUSAP1 compared with the si-NC and blank group in the 786-O (A) and A704 (B) cell lines. Data are shown as mean $\pm \mathrm{SD}(\mathrm{n}=3) ;{ }^{* *} \mathrm{P}<0.001$.

$(\mathrm{P}=0.023)$, while no significant correlation was found between NUSAP1 expression and gender, age and lymph node metastasis $(\mathrm{P}>0.05)$.

NUSAP1 expression predicts the prognosis of ccRCC patients. The association between NUSAP1 expression and the prognosis of ccRCC patients was analyzed by Kaplan-Meier method. The 5-year survival rate in the group of patients with high NUSAP1 expression was $61.8 \%$, whereas it was increased to $78.6 \%$ for these patients with low NUSAP1 expression (Fig. 2E). The log-rank test was used to compare the correlation between survival and NUSAP1 expression in the low and high expression groups. Our results suggested that the patients with low NUSAP1 expression had a significantly longer overall survival (OS) time than those with high NUSAP1 expression $(\mathrm{P}=0.006)$.

NUSAP1 downregulation suppresses the growth and aggressiveness of RCC cells in vitro. As shown in Fig. $1 \mathrm{C}$ and D, three RCC cell lines (A704, 786-O and ACHN) 
A
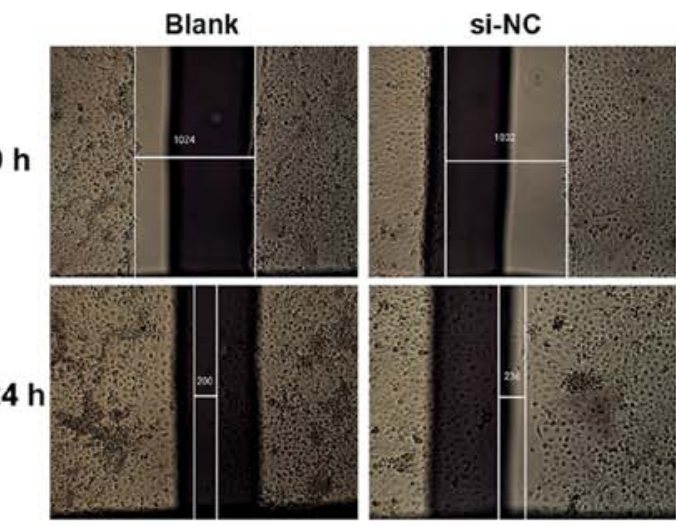

$24 \mathrm{~h}$

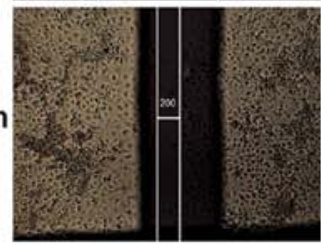

B

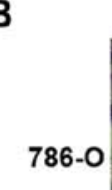

si-NC
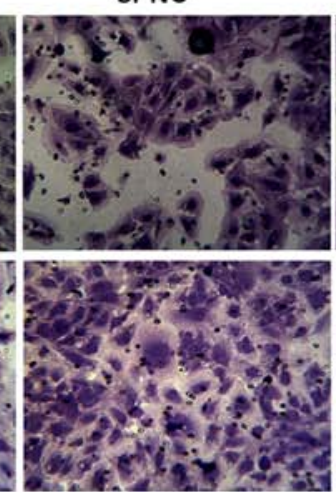
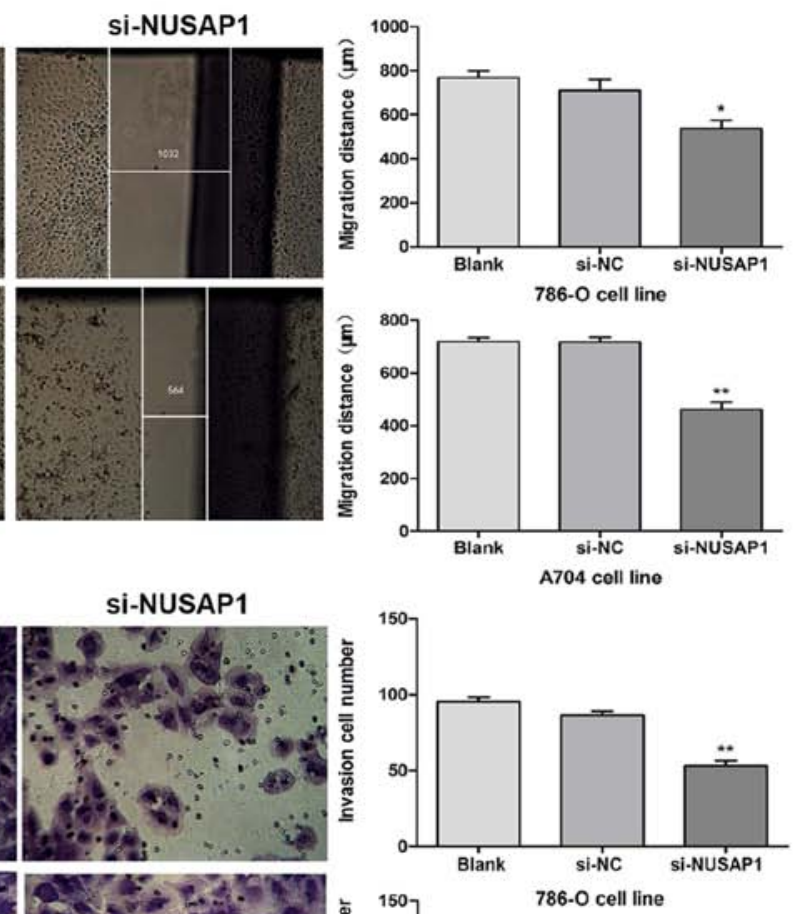

A704
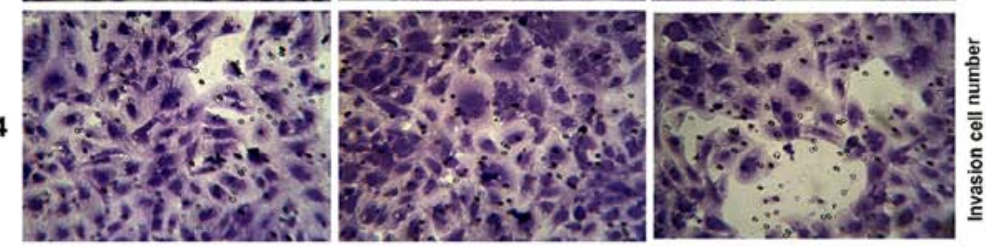

C

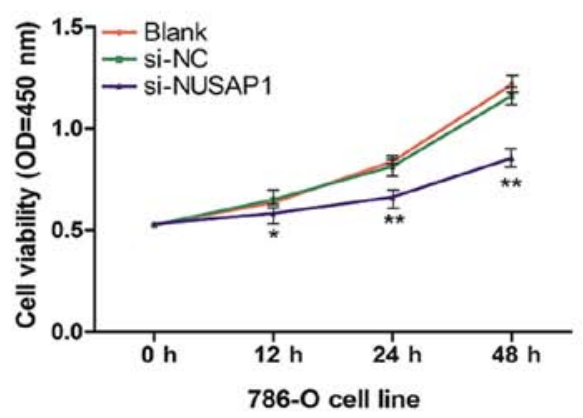

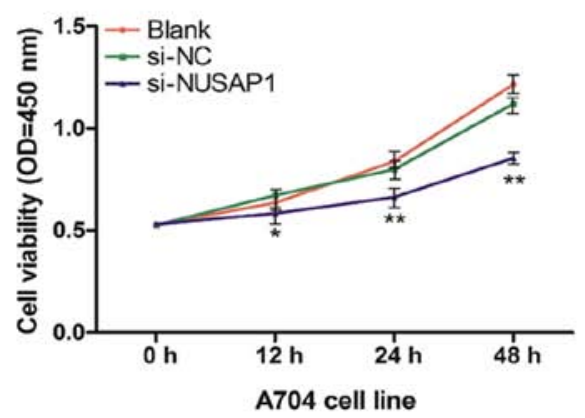

Figure 4. Downregulation of NUSAP1 expression suppresses migration, invasion and proliferation in the 786-O and A704 cells. (A) Scratch migration assay showed an obviously shorter migration distance in the 786-O and A704 cells treated with si-NUSAP1 (magnification, x40). (B) Matrigel invasion assay showed that the number of invaded cells was significantly decreased after transfection with si-NUSAP1 in the 786-O and A704 cells (magnification, x100). (C) Cells transfected with si-NUSAP1 showed a lower viability as determined by CCK-8 assay (at $0,12,24$ and $48 \mathrm{~h}$ ). The data are expressed as mean \pm SD ( $\mathrm{n}=3$ ), compared with the blank and si-NC group; ${ }^{*} \mathrm{P}<0.05,{ }^{* *} \mathrm{P}<0.001$.

exhibited an obviously increased expression of NUSAP1. We thus chose A704 and 786-O cell lines to determine the biological behaviors of human RCC cell lines following the downregulation of NUSAP1 expression in vitro. After transfection with siRNA targeting NUSAP1 (si-NUSAP1), cells exhibited a significant decrease in mRNA and protein levels of NUSAP1 compared with those transfected with scrambled siRNA (si-NC) (Fig. 3A and B; P<0.001). Our results suggested that the NUSAP1 expression was efficiently downregulated in the human RCC cells in vitro.

Moreover, we performed scratch migration, Transwell invasion and CCK- 8 assays to investigate the effects of the downregulation of NUSAP1 on cell migration, invasion and proliferation in the two RCC cell lines (A704 and 786-O), respectively. The results showed that downregulation of
NUSAP1 by siRNA caused a significant inhibition of cell migration of the 786-O $(\mathrm{P}<0.05)$ and $\mathrm{A} 704(\mathrm{P}<0.001)$ cell lines (Fig. 4A). In accordance with this result, downregulation of NUSAP1 also resulted in a clear decrease in cell invasive ability (Fig. 4B; $\mathrm{P}<0.001$ ). In the CCK-8 assay, we found that the proliferation rate of the cells transfected with si-NUSAP1 was significantly decreased compared with the rate in the cells treated with si-NC/blank (Fig. 4C; $\mathrm{P}<0.05, \mathrm{P}<0.001)$. In summary, these results indicated that NUSAP1 expression was closely associated with cell growth and aggressiveness of RCC.

NUSAP1 downregulation induces apoptosis and cell cycle arrest of RCC cells. To further investigate the mechanism of cell growth inhibition by downregulation of NUSAP1 
A

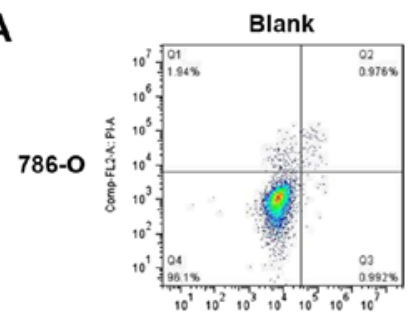

comortia neopurton

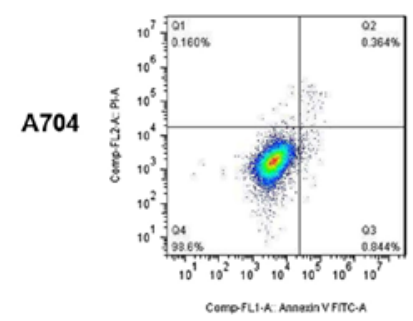

B
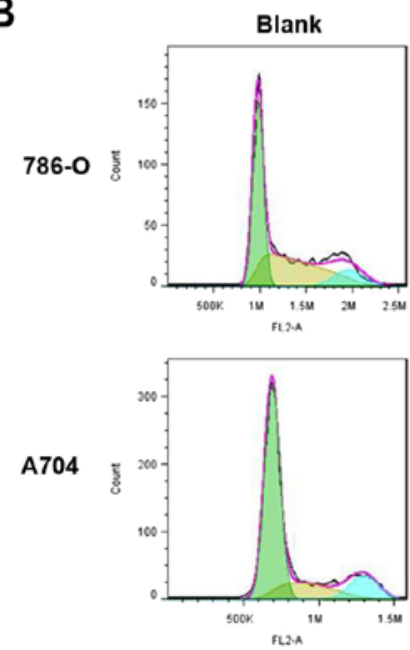
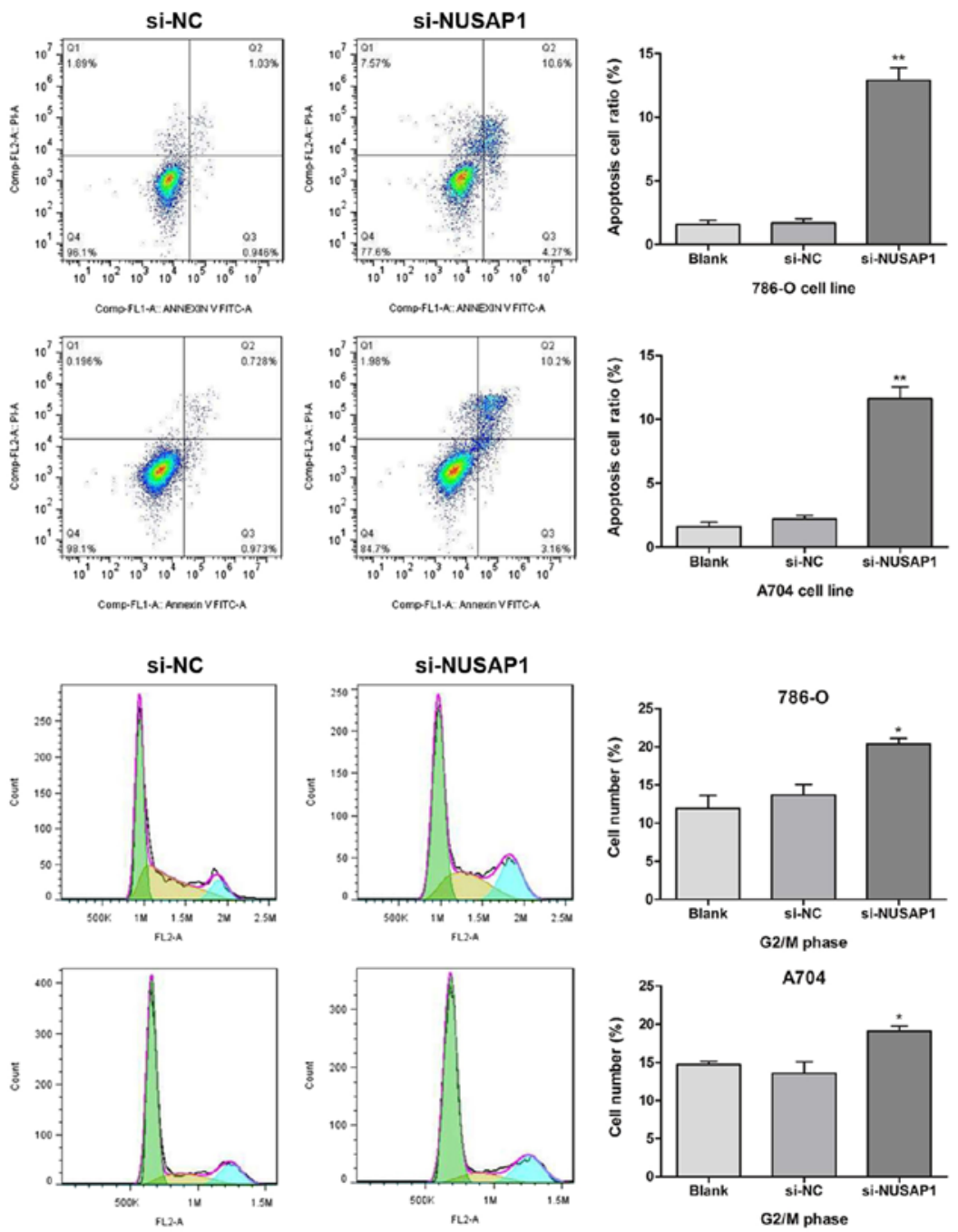

Figure 5. Downregulation of NUSAP1 expression induces the apoptosis and cell cycle arrest of RCC cells. (A) Apoptosis assay indicated that transfection with si-NUSAP1 resulted in a significant increase in apoptosis in the 786-O and A704 cells. (B) According to flow cytometric analysis, downregulation of NUSAP1 expression resulted in a significant increase in the cell rate of $\mathrm{G} 2 / \mathrm{M}$ phase in $786-\mathrm{O}$ and $\mathrm{A} 704$ cells; ${ }^{*} \mathrm{P}<0.05,{ }^{* *} \mathrm{P}<0.001$.

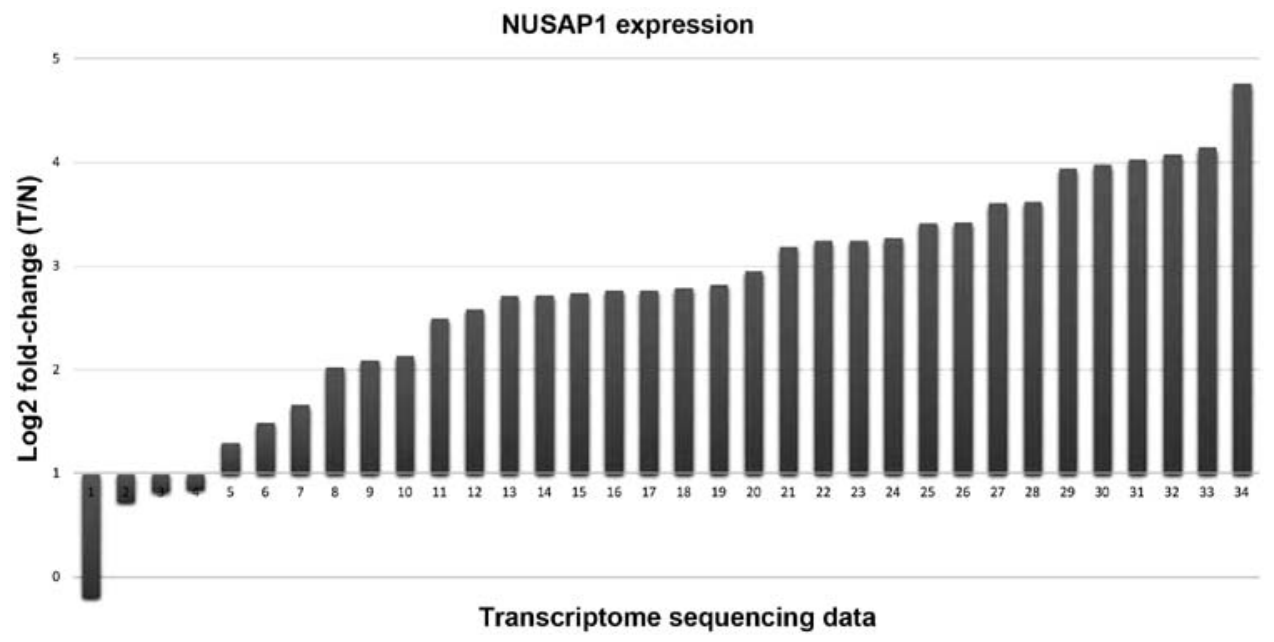

Figure 6. Expression level of NUSAP1 was determined in 34 matched pairs of RCC and adjacent normal tissues by transcriptome sequencing.

expression in RCC cells, the cell cycle progression of 786-O and A704 cells was analyzed using flow cytometry. As shown in Fig. 5B, after transfection with si-NUSAP1, a higher rate of $\mathrm{G}_{2} / \mathrm{M}$ phase arrest when compared with that in the si-NC 
Table II. Detail information of the copy number alterations of NUSAP1 in each tumor.

\begin{tabular}{|c|c|c|c|c|c|c|c|c|c|c|}
\hline Gene_ID & Tumor_ID & $\mathrm{Chr}$ & Start & End & $\mathrm{Np}$ & Mean & Arm & Snvs & $\mathrm{Ai}$ & Median \\
\hline NUSAP1 & s0 & $\operatorname{chr} 15$ & 25350206 & 102504996 & 7698 & -0.0109 & $q$ & 55200 & 0.279345089 & 1 \\
\hline NUSAP1 & s10 & $\operatorname{chr} 15$ & 38728401 & 46001801 & 728 & -0.2991 & $q$ & 3287 & 0.315852751 & 0.807955743 \\
\hline NUSAP1 & s100 & $\operatorname{chr} 15$ & 40759001 & 42050401 & 130 & 0.414 & $q$ & 1062 & 0.275158292 & 1.327034164 \\
\hline NUSAP1 & s102 & $\operatorname{chr} 15$ & 20709801 & 64638001 & 4319 & 0.1043 & $q$ & 31445 & 0.27427683 & 1.068181818 \\
\hline NUSAP1 & s104 & $\operatorname{chr} 15$ & 21360641 & 102503196 & 8030 & 0.1958 & $q$ & 57702 & 0.284325477 & 1.142857143 \\
\hline NUSAP1 & s106 & $\operatorname{chr} 15$ & 20709801 & 71496601 & 5004 & 0.2211 & $q$ & 37642 & 0.337889277 & 1.166666667 \\
\hline NUSAP1 & s108 & chr15 & 20709801 & 66594801 & 4514 & -0.0064 & $\mathrm{q}$ & 36556 & 0.303544235 & 1 \\
\hline NUSAP1 & s110 & $\operatorname{chr} 15$ & 25501806 & 65942601 & 4038 & -0.0802 & $\mathrm{q}$ & 28232 & 0.27952482 & 0.951456311 \\
\hline NUSAP1 & s112 & $\operatorname{chr} 15$ & 20709801 & 102504396 & 8092 & 0.0516 & $q$ & 59613 & 0.289589089 & 1.03960396 \\
\hline NUSAP1 & s120 & $\operatorname{chr} 15$ & 20709801 & 102502796 & 8091 & 0.1149 & $q$ & 63673 & 0.286246703 & 1.081632653 \\
\hline NUSAP1 & s122 & $\operatorname{chr} 15$ & 41332001 & 41952801 & 63 & 0.2006 & $q$ & 374 & 0.273066667 & 1.153 \\
\hline NUSAP1 & s124 & $\operatorname{chr} 15$ & 20709801 & 102505396 & 8092 & 0.0726 & $q$ & 61169 & 0.289522145 & 1.051020408 \\
\hline NUSAP1 & s126 & $\operatorname{chr} 15$ & 20709801 & 102503996 & 8092 & 0.1222 & $\mathrm{q}$ & 61144 & 0.300015989 & 1.082413584 \\
\hline NUSAP1 & s128 & $\operatorname{chr} 15$ & 20709801 & 68051801 & 4660 & -0.3636 & $q$ & 31259 & 0.465118203 & 0.7757 \\
\hline NUSAP1 & s14 & $\operatorname{chr} 15$ & 20709801 & 102507796 & 8094 & 0.0218 & $\mathrm{q}$ & 62011 & 0.291422215 & 1.018181818 \\
\hline NUSAP1 & s16 & $\operatorname{chr} 15$ & 24729806 & 102505996 & 7759 & -0.2949 & $q$ & 42076 & 0.740367921 & 0.815789474 \\
\hline NUSAP1 & s18 & $\operatorname{chr} 15$ & 20709801 & 62136001 & 4068 & 0.0365 & $q$ & 29248 & 0.3156 & 297 \\
\hline NUSAP1 & s20 & $\operatorname{chr} 15$ & 20709801 & 1025 & 8092 & -0.1055 & $\mathrm{q}$ & 59054 & 0.3001 & 0.9 \\
\hline NUSAP1 & s22 & $\operatorname{chr} 15$ & 20709801 & 102502396 & 8094 & 0.0815 & $q$ & 784 & 0.2852 & 9775 \\
\hline NUSAP1 & s24 & $\operatorname{chr} 15$ & 20709801 & 102383796 & 8082 & -0.0322 & $q$ & 59942 & 0.30840 & 47368 \\
\hline NUSAP1 & s26 & $\operatorname{chr} 15$ & 20709801 & 102504596 & 8094 & -0.0281 & $\mathrm{q}$ & 59679 & 0.304 & 0.988303694 \\
\hline NUSAP1 & s28 & $\operatorname{chr} 15$ & 20709801 & 102509796 & 8095 & -0.1533 & $q$ & 60822 & 0.30586 & 0.9 \\
\hline NUSAP1 & s30 & $\operatorname{chr} 15$ & 20709801 & 102506796 & 8094 & 0.1142 & $\mathrm{q}$ & 60481 & 0.2989 & 1.08 \\
\hline NUSAP1 & s32 & $\operatorname{chr} 15$ & 2070 & 102 & 8094 & 0.0 & $q$ & 61255 & 0.31 & 376 \\
\hline NUSAP1 & s34 & $\operatorname{chr} 15$ & 2070 & 1025 & 8094 & 0.0188 & $q$ & 59756 & 0.2 & 9308 \\
\hline NUSAP1 & s36 & $\operatorname{chr} 15$ & 20709801 & 102028996 & 8047 & -0.0725 & $q$ & 61481 & 0.286 & 0.96 \\
\hline NUSAP1 & s38 & $\operatorname{chr} 15$ & 25501806 & 102507996 & 7682 & 0.0417 & $\mathrm{q}$ & 184 & 0.281 & 1.02857 \\
\hline NUSAP1 & s4 & $\operatorname{chr} 15$ & 20709801 & 102509396 & 8084 & -0.0308 & $\mathrm{q}$ & 61369 & 0.304033643 & 0.97979798 \\
\hline NUSAP1 & s40 & $\operatorname{chr} 15$ & 20709801 & 102510396 & 8093 & 0.0192 & $q$ & 56548 & 0.306970417 & 1.01369863 \\
\hline NUSAP1 & s42 & $\operatorname{chr} 15$ & 20709801 & 102508196 & 8095 & -0.0408 & $q$ & 61258 & 0.2 & 47368 \\
\hline NUSAP1 & s44 & $\operatorname{chr} 15$ & 20709801 & 1025 & 8095 & -0.047 & $q$ & 63256 & 0.2 & 0.9 \\
\hline NUSAP1 & s46 & chr15 & 40788201 & 42078801 & 130 & -0.865 & $\mathrm{q}$ & 233 & 0.895454545 & 0.555555556 \\
\hline NUSAP1 & s48 & chr15 & 20704991 & 100335961 & 15656 & 0.0227 & $q$ & 60839 & 0.284898937 & 1.015151515 \\
\hline NUSAP1 & s50 & $\operatorname{chr} 15$ & 31687371 & 100337196 & 13679 & 0.1568 & $\mathrm{q}$ & 49530 & 0.25923184 & 1.125 \\
\hline NUSAP1 & s52 & $\operatorname{chr} 15$ & 20709801 & 102501596 & 8094 & -0.0348 & $\mathrm{q}$ & 59474 & 0.287460229 & 0.98757716 \\
\hline NUSAP1 & s54 & $\operatorname{chr} 15$ & 20709801 & 102506796 & 8082 & -0.0881 & $\mathrm{q}$ & 65229 & 0.307597479 & 0.946236559 \\
\hline NUSAP1 & s56 & $\operatorname{chr} 15$ & 7406 & 96845596 & 7194 & -0.6389 & $q$ & 37315 & 0.7 & 0.6 \\
\hline NUSAP1 & s58 & $\operatorname{chr} 15$ & 20709801 & 102510396 & 8092 & 0.0182 & $\mathrm{q}$ & 61613 & 0.302473804 & 1.014925373 \\
\hline NUSAP1 & s6 & chr15 & 20709801 & 102509996 & 8094 & 0.1546 & $q$ & 60593 & 0.280029132 & 1.112359551 \\
\hline NUSAP1 & s60 & chr15 & 20709801 & 102506196 & 8090 & 0.1564 & $\mathrm{q}$ & 54711 & 0.290879563 & 1.11627907 \\
\hline NUSAP1 & s62 & $\operatorname{chr} 15$ & 20709801 & 102507396 & 8093 & 0.0699 & $\mathrm{q}$ & 62295 & 0.293077342 & 1.050505051 \\
\hline NUSAP1 & s64 & $\operatorname{chr} 15$ & 20709801 & 89873396 & 6829 & -0.0218 & $q$ & 51236 & 0.285149303 & 0.989361702 \\
\hline NUSAP1 & s66 & $\operatorname{chr} 15$ & 28875606 & 60649801 & 3171 & -0.6257 & $q$ & 23826 & 0.320973335 & 0.647887324 \\
\hline NUSAP1 & s68 & $\operatorname{chr} 15$ & 20709801 & 102440796 & 8078 & -0.402 & $\mathrm{q}$ & 61877 & 0.338655047 & 0.75862069 \\
\hline NUSAP1 & s70 & $\operatorname{chr} 15$ & 20709801 & 102503996 & 8092 & 0.0921 & $q$ & 58793 & 0.288186153 & 1.064516129 \\
\hline NUSAP1 & s72 & $\operatorname{chr} 15$ & 20709801 & 102508396 & 8086 & 0.389 & $\mathrm{q}$ & 62189 & 0.273379856 & 1.307692308 \\
\hline NUSAP1 & s74 & $\operatorname{chr} 15$ & 20709801 & 102503996 & 8093 & -0.0213 & $\mathrm{q}$ & 63626 & 0.311079859 & 0.99009901 \\
\hline NUSAP1 & s76 & $\operatorname{chr} 15$ & 20709801 & 93391196 & 7182 & 855 & $\mathrm{q}$ & 52133 & 0.28283461 & 1.216981132 \\
\hline NUSAP1 & s78 & chris & 20789801 & 102506196 & 8085 & -0.0992 & $\mathrm{q}$ & 62903 & 0.314847052 & 0.931818182 \\
\hline NUSAP1 & s8 & $\operatorname{chr} 15$ & 20709801 & 102507596 & 8094 & -0.0214 & $q$ & 63291 & 0.291604673 & 0.989130435 \\
\hline NUSAP1 & s80 & $\operatorname{chr} 15$ & 20709801 & 102508196 & 8092 & 0.1063 & $\mathrm{q}$ & 57907 & 0.280533032 & 1.075949367 \\
\hline NUSAP1 & s82 & $\operatorname{chr} 15$ & 20709801 & 90512996 & 6894 & 0.0514 & $\mathrm{q}$ & 51402 & 0.385165292 & 1.033333333 \\
\hline
\end{tabular}


Table II. Continued.

\begin{tabular}{lcccrrrrrrr}
\hline Gene_ID & Tumor_ID & Chr & Start & End & Np & Mean & Arm & Snvs & Ai & Median \\
\hline NUSAP1 & s84 & chr15 & 20709801 & 102502396 & 8092 & -0.1288 & $\mathrm{q}$ & 59308 & 0.354867788 & 0.915789474 \\
NUSAP1 & $\mathrm{s} 86$ & $\mathrm{chr15}$ & 20709801 & 102503796 & 8092 & -0.0767 & $\mathrm{q}$ & 61377 & 0.289897677 & 0.949494949 \\
NUSAP1 & $\mathrm{s} 88$ & $\mathrm{chr15}$ & 20709801 & 102504196 & 8091 & -0.0986 & $\mathrm{q}$ & 59518 & 0.306860135 & 0.94 \\
NUSAP1 & $\mathrm{s} 90$ & $\mathrm{chr15}$ & 25350206 & 102502196 & 7697 & 0.2473 & $\mathrm{q}$ & 55249 & 0.255991001 & 1.184466019 \\
NUSAP1 & $\mathrm{s} 92$ & $\mathrm{chr15}$ & 21370441 & 50571201 & 2851 & 0.3202 & $\mathrm{q}$ & 21738 & 0.287522867 & 1.266055046 \\
NUSAP1 & $\mathrm{s} 94$ & $\mathrm{chr15}$ & 20709801 & 75322201 & 5387 & -0.0493 & $\mathrm{q}$ & 37385 & 0.311031557 & 0.962962963 \\
NUSAP1 & $\mathrm{s} 96$ & $\mathrm{chr15}$ & 41269201 & 42020001 & 76 & 0.0274 & $\mathrm{q}$ & 215 & 0.346910112 & 1.026491228 \\
NUSAP1 & $\mathrm{s} 98$ & $\mathrm{chr15}$ & 20709801 & 102509196 & 8091 & 0.0142 & $\mathrm{q}$ & 58809 & 0.286709788 & 1.009615385 \\
NUSAP1 & $\mathrm{s} 999$ & $\mathrm{chr15}$ & 20709801 & 67311401 & 4586 & -0.0995 & $\mathrm{q}$ & 33217 & 0.281856442 & 0.946236559 \\
\hline
\end{tabular}

NUSAP, nucleolar and spindle-associated protein 1.

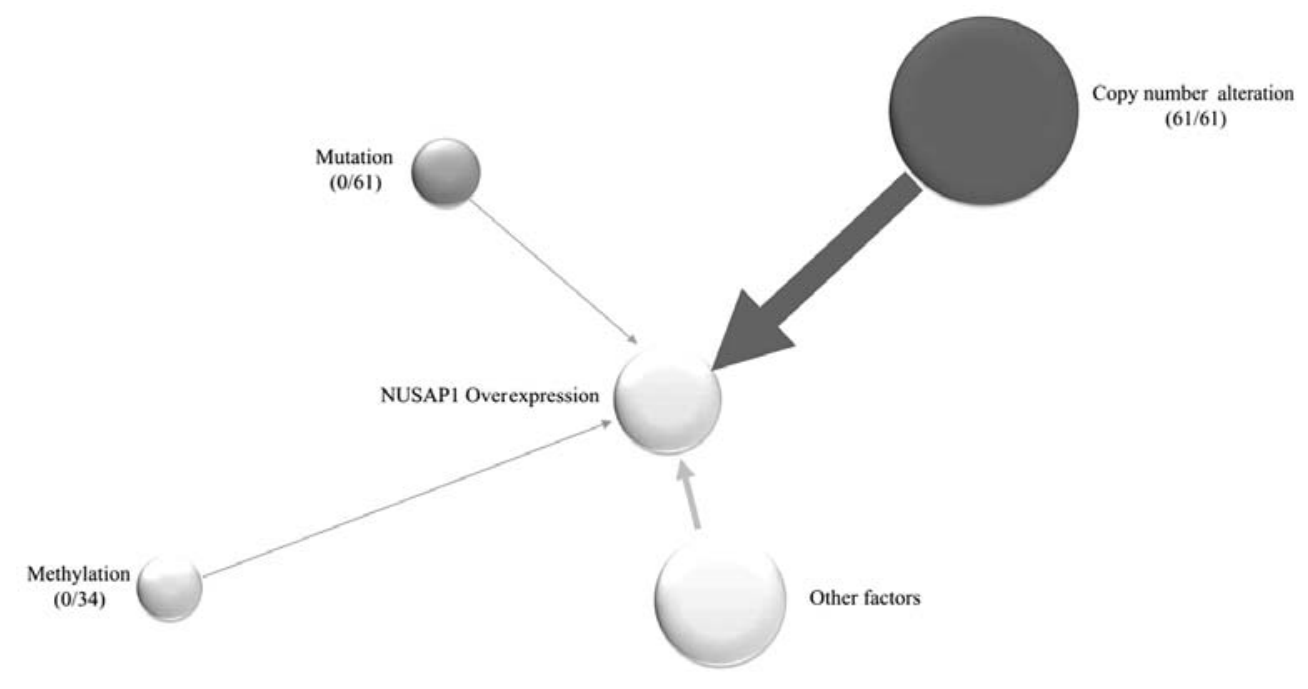

Figure 7. Potential influence factors accounting for the overexpression of NUSAP1 (including mutation, methylation, copy number alteration and other factors).

group (mean rate, 20.37 vs. 13.69\%; $\mathrm{P}<0.05$ ) was identified in the 786-O cells, as well as in the A704 cells (mean rate, 19.11 vs. $13.59 \%$; $\mathrm{P}<0.05)$. Moreover, flow cytometric analysis showed that there was a higher percentage of apoptotic cells in the si-NUSAP1-transfected RCC cells, when compared with this percentage in cells treated with si-NC (Fig. 5A; $\mathrm{P}<0.001$ ). Therefore, our results suggest that downregulation of NUSAP1 expression could induce apoptosis and cell cycle arrest of RCC cells.

Copy number alterations (CNAs) influence the expression of NUSAP1. We analyzed the RBBS-seq data, and no methylation variation of the promoter region of NUSAP1 $(0 / 34,0 \%)$ was identified by quantitative analysis. However, when analyzing the transcriptome data, we identified that NUSAP1 was overexpressed in 30 of the 34 paired RCCs relative to the adjacent normal controls (Fig. 6). Intriguingly, we identified that CNAs of the NUSAP1 region existed in all of the 61 paired RCCs (61/61, 100\%) (Fig. 7 and Table II). Thus, we assumed that the overexpression of NUSAP1 in RCC was mostly due to CNAs.
All of the analysis pipelines were referred to in our previous study (18).

\section{Discussion}

Tremendous advances have been made over the last decade in our understanding of the genetic basis and progress of a targeted therapeutic armamentarium for RCC. As is known to all, various conventional agents that target the vascular endothelial growth factor (VEGF) pathway or mammalian target of rapamycin (mTOR) may benefit renal cell carcinoma (RCC) patients (19). However, despite more options and advances in treatment, most patients with advanced disease still exhibit a markedly poor outcome, and we have not yet elucidated the mechanism behind its development (20). Therefore, continued research to identify more genes which drive the initiation and progression of RCC is clearly warranted.

The function of NUSAP1 has been investigated in several recent studies, which demonstrate its crucial role in cell mitosis and tumorigenesis (6). Although, the overexpression 
of NUSAP1 at the mRNA level has been found in several types of cancers, there is limited research concentrating on the expression and clinical significance of NUSAP1 in RCC. Our previous transcriptome sequencing data indicated that the expression level of NUSAP1 was significantly higher in RCC tissues than that in matched adjacent normal tissues. Methylation of high-density $\mathrm{CpG}$ regions known as $\mathrm{CpG}$ islands (CGIs) has been widely described as a mechanism associated with gene expression regulation (21), whereas no methylation change of NUSAP1 $(0 / 34,0 \%)$ was identified in the present study. In addition, in a previous study using both transcriptional profile data and CNA, they identified that genes with differential expression may be caused by CNAs (22). To our surprise, CNAs of NUSAP1 existed in all of the 61 paired RCCs, which suggest that CNAs could be the primary cause for the overexpression of NUSAP1 in RCC.

Next, we determined the mRNA and protein levels of NUSAP1 expression in 38 pairs of ccRCC and matched normal tissues and five cell lines (including four RCC cell lines and the HK-2 cell line). The qRT-PCR and western blot analyses showed that NUSAP1 was relatively overexpressed in the RCC tissues, as well as in three RCC cell lines (A704, 786-O and ACHN). Our data demonstrated that an elevated expression of NUSAP1 at the transcription and translation levels may closely correlate with the tumorigenesis of RCC, and NUSAP1 may be a potential indicator for RCC patients. In addition, immunohistochemical analysis was performed to determine the association between NUSAP1 expression and clinicopathological characteristics of the ccRCC patients. The results showed that NUSAP1 expression was significantly associated with the level of malignancy of ccRCC. Namely, upregulation of NUSAP1 was associated with aggressive features of ccRCC, such as Fuhrman grade, tumor size, clinical stage and metastasis. In various recent studies, NUSAP1 expression was found to be associated with the poor prognosis of patients with melanoma (10), and NUSAP1 was also identified as part of a malignancy-risk gene signature for breast cancer (14). Consistent with these studies, our survival analysis similarly revealed that overexpression of NUSAP1 was obviously correlated with a shorter overall survival time of ccRCC patients. These results suggest that NUSAP1 could play an important role in the progression of RCC.

In attempting to determine the biological role of NUSAP1 in RCC, we performed a series of functional experiments after downregulation of NUSAP1 expression in vitro. In the si-NUSAP1-transfected cell lines, the migration, proliferation and invasion of RCC cells were significantly inhibited compared with the control groups. A study by Gordon et al (23) demonstrated that knockdown of NUSAP1 by siRNA reduced the proliferation and invasion in prostate cancer cell lines, suggested that NUSAP1 could influence tumor cell growth and aggressiveness. Furthermore, Nie et al (24) found that NUSAP1 depletion blocked the migration of neural crest cells in zebrafish embryos, which indicates that its overexpression may promote cancer cell migration. As we mentioned earlier, NUSAP1 is a microtubule-binding protein that is selectively expressed in proliferating cells. Its depletion causes G2/M arrest in cell cycle progression. In the present study, we also discovered that downregulation of NUSAP1 induced apoptosis and $\mathrm{G} 2 / \mathrm{M}$ arrest of RCC cells. In agreement with our results, knockdown of NUSAP1 by siRNA in HeLa cells also led to mitotic arrest and abnormal chromosome condensation (7). In addition, Vanden Bosch et al (8) found the rapid disintegration and small cellular fragments were present in reduced growth of NUSAP1-null mice embryos, and presumed that lack of NUSAP1 may result in apoptosis. Based on its crucial role in mitosis, and NUSAP1 depletion suppressed cell growth and induced apoptosis, we thus assumed that it could represent a novel therapeutic target for RCC patients.

In conclusion, we demonstrated that NUSAP1 overexpression was closely related to the clinicopathological features of RCC and predicted an unfavorable prognosis for RCC patients. Downregulation of NUSAP1 induced cell apoptosis and inhibited cell migration, proliferation and invasion. NUSAP1 may thus serve as a potential prognostic indicator and a novel therapeutic target for RCC patients. However, our research is only a preliminary discussion on the expression and biological function of NUSAP1 in RCC. Further studies are necessary to confirm these findings and uncover the mechanisms of these processes.

\section{Acknowledgements}

The present study was supported by grants from the National Natural Science Foundation of China (nos. 81301740 and 81402336).

\section{References}

1. Chow WH, Dong LM and Devesa SS: Epidemiology and risk factors for kidney cancer. Nat Rev Urol 7: 245-257, 2010.

2. Lam JS, Shvarts O, Leppert JT, Figlin RA and Belldegrun AS: Renal cell carcinoma 2005: New frontiers in staging, prognostication and targeted molecular therapy. J Urol 173: 1853-1862, 2005.

3. Ferlay J, Shin HR, Bray F, Forman D, Mathers C and Parkin DM: Estimates of worldwide burden of cancer in 2008: GLOBOCAN 2008. Int J Cancer 127: 2893-2917, 2010.

4. Athar U and Gentile TC: Treatment options for metastatic renal cell carcinoma: A review. Can J Urol 15: 3954-3966, 2008.

5. Gupta K, Miller JD, Li JZ, Russell MW and Charbonneau C: Epidemiologic and socioeconomic burden of metastatic renal cell carcinoma (mRCC): A literature review. Cancer Treat Rev 34: 193-205, 2008.

6. Iyer J, Moghe S, Furukawa M and Tsai MY: What's Nu(SAP) in mitosis and cancer? Cell Signal 23: 991-998, 2011.

7. Raemaekers T, Ribbeck K, Beaudouin J, Annaert W, Van Camp M, Stockmans I, Smets N, Bouillon R, Ellenberg J and Carmeliet G: NuSAP, a novel microtubule-associated protein involved in mitotic spindle organization. J Cell Biol 162: 1017-1029, 2003.

8. Vanden Bosch A, Raemaekers T, Denayer S, Torrekens S, Smets N, Moermans K, Dewerchin M, Carmeliet P and Carmeliet G: NuSAP is essential for chromatin-induced spindle formation during early embryogenesis. J Cell Sci 123: 3244-3255, 2010.

9. Kokkinakis DM, Liu X and Neuner RD: Modulation of cell cycle and gene expression in pancreatic tumor cell lines by methionine deprivation (methionine stress): Implications to the therapy of pancreatic adenocarcinoma. Mol Cancer Ther 4: 1338-1348, 2005.

10. Bogunovic D, O'Neill DW, Belitskaya-Levy I, Vacic V, Yu YL, Adams S, Darvishian F, Berman R, Shapiro R, Pavlick AC, et al: Immune profile and mitotic index of metastatic melanoma lesions enhance clinical staging in predicting patient survival. Proc Natl Acad Sci USA 106: 20429-20434, 2009.

11. Marie SK, Okamoto OK, Uno M, Hasegawa AP, Oba-Shinjo SM, Cohen T, Camargo AA, Kosoy A, Carlotti CG Jr, Toledo S, et al: Maternal embryonic leucine zipper kinase transcript abundance correlates with malignancy grade in human astrocytomas. Int J Cancer 122: 807-815, 2008 . 
12. Satow R, Shitashige M, Kanai Y, Takeshita F, Ojima H, Jigami T, Honda K, Kosuge T, Ochiya T, Hirohashi S, et al: Combined functional genome survey of therapeutic targets for hepatocellular carcinoma. Clin Cancer Res 16: 2518-2528, 2010.

13. Gulzar ZG, McKenney JK and Brooks JD: Increased expression of $N u S A P$ in recurrent prostate cancer is mediated by $E 2 F 1$. Oncogene 32: 70-77, 2013.

14. Chen DT, Nasir A, Culhane A, Venkataramu C, Fulp W, Rubio R, Wang T, Agrawal D, McCarthy SM, Gruidl M, et al: Proliferative genes dominate malignancy-risk gene signature in histologicallynormal breast tissue. Breast Cancer Res Treat 119: 335-346, 2010.

15. Lauss M, Kriegner A, Vierlinger K, Visne I, Yildiz A, Dilaveroglu E and Noehammer C: Consensus genes of the literature to predict breast cancer recurrence. Breast Cancer Res Treat 110: 235-244, 2008.

16. Cario G, Fetz A, Bretscher C, Möricke A, Schrauder A, Stanulla $M$ and Schrappe M: Initial leukemic gene expression profiles of patients with poor in vivo prednisone response are similar to those of blasts persisting under prednisone treatment in childhood acute lymphoblastic leukemia. Ann Hematol 87 709-716, 2008.

17. Livak KJ and Schmittgen TD: Analysis of relative gene expression data using real-time quantitative PCR and the $2-\Delta \Delta C_{\mathrm{T}}$ method. Methods 25: 402-408, 2001.
18. Huang Y, Gao S, Wu S, Song P, Sun X, Hu X, Zhang S, Yu Y, Zhu J, Li C, et al: Multilayered molecular profiling supported the monoclonal origin of metastatic renal cell carcinoma. Int J Cancer 135: 78-87, 2014.

19. Srinivasan R, Ricketts CJ, Sourbier C and Linehan WM: New strategies in renal cell carcinoma: Targeting the genetic and metabolic basis of disease. Clin Cancer Res 21: 10-17, 2015.

20. Jonasch E and Motzer RJ: Ten years of progress in renal cell carcinoma. J Natl Compr Canc Netw 10: 690-693, 2012.

21. Moarii M, Boeva V, Vert JP and Reyal F: Changes in correlation between promoter methylation and gene expression in cancer. BMC Genomics 16: 873, 2015.

22. Yang Z, Zhuan B, Yan Y, Jiang S and Wang T: Integrated analyses of copy number variations and gene differential expression in lung squamous-cell carcinoma. Biol Res 48: 47, 2015.

23. Gordon CA, Gulzar ZG and Brooks JD: NUSAP1 expression is upregulated by loss of RB1 in prostate cancer cells. Prostate 75: 517-526, 2015.

24. Nie J, Wang H, He F and Huang H: Nusap1 is essential for neural crest cell migration in zebrafish. Protein Cell 1: 259-266, 2010. 